\title{
Journal of Management
}

\section{If You Wrong Us, Shall We Not Revenge? Moderating Roles of Self-Control and Perceived Aggressive Work Culture in Predicting Responses to Psychological Contract Breach}

Simon Lloyd D. Restubog, Thomas J. Zagenczyk, Prashant Bordia, Sarbari Bordia and Georgia J. Chapman

Journal of Management published online 8 May 2012

DOI: $10.1177 / 0149206312443557$

The online version of this article can be found at:

http://jom.sagepub.com/content/early/2012/05/03/0149206312443557

Published by:

(\$)SAGE

http://www.sagepublications.com

On behalf of:

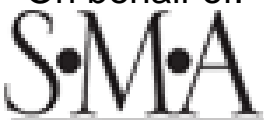

SOUTHERN

MANAGEMENT

Southern Management Association

Additional services and information for Journal of Management can be found at:

Email Alerts: http://jom.sagepub.com/cgi/alerts

Subscriptions: http://jom.sagepub.com/subscriptions

Reprints: http://www.sagepub.com/journalsReprints.nav

Permissions: http://www.sagepub.com/journalsPermissions.nav

>> OnlineFirst Version of Record - May 8, 2012

What is This? 
Journal of Management

Vol. XX No. X, Month XXXX xx-xx

DOI: $10.1177 / 0149206312443557$

(C) The Author(s) 2012

Reprints and permission: http://www.

sagepub.com/journalsPermissions.nav

\title{
If You Wrong Us, Shall We Not Revenge? Moderating Roles of Self-Control and Perceived Aggressive Work Culture in Predicting Responses to Psychological Contract Breach
}

\author{
Simon Lloyd D. Restubog \\ The Australian National University \\ Thomas J. Zagenczyk \\ Clemson University \\ Prashant Bordia \\ Sarbari Bordia \\ The Australian National University \\ Georgia J. Chapman \\ The University of New South Wales
}

The authors develop and test a moderated mediation model that accounts for employee emotions (psychological contract violation), employee motivation (revenge cognitions), employee personality (self-control), and context (perceived aggressive culture) in the relationship between psychological contract breach and workplace deviance. In Sample 1, involving 146 hospitality workers and their peers, the authors found support for a conditional indirect effect of psychological contract violation in predicting workplace deviance via revenge cognitions for those employees who perceive a high as opposed to low aggressive work culture. In addition, they

Acknowledgments: The first and second authors contributed equally in writing this manuscript. We thank Chris Asuncion, Patrick Garcia, Franco Quodala, and Lemuel Toledano for research assistance. This research was supported by Australian Research Council grants to the first (DP1094023) and the third (DP1096037) authors.

Corresponding author: Simon Lloyd D. Restubog, Research School of Management, The Australian National University, Level 1, LF Crisp Building, ANM, ACT, 0200, Australia

E-mail: Simon.Restubog@anu.edu.au 
found that at high levels of perceived aggressive work culture, the conditional indirect effects of psychological contract violation in predicting workplace deviance via revenge cognitions were statistically significant for those employees with low as opposed to high self-control. These results were replicated in Sample 2 using an independent sample of 168 hospitality workers in a different cultural context. Overall, the results suggest that self-control and perceived aggressive culture, taken together, influence the enactment of deviant acts. Implications for research and practice are discussed.

Keywords: psychological contracts; psychological contract breach; revenge; individual differences; organizational culture; self-control; workplace deviance

Successful management of the employer-employee relationship depends on the degree to which organizations fulfill employees' psychological contracts. Such contracts are mental models that encapsulate the perceived promises employees believe the organization has made to them in exchange for their efforts (Rousseau, 1995). Researchers of psychological contracts have compiled a great deal of evidence attesting to the negative outcomes that occur when psychological contracts are not fulfilled (termed psychological contract breach), including reduced performance, poor work attitudes, withdrawal behaviors (Restubog, Bordia, \& Bordia, 2011; Zhao, Wayne, Glibkowski, \& Bravo, 2007), and workplace deviance (Bordia, Restubog, \& Tang, 2008). Notably, the idiosyncratic nature of psychological contracts and the rapidly changing business environment have made breach a common (Robinson \& Morrison, 2000) or even inevitable (Kiewitz, Restubog, Zagenczyk, \& Hochwarter, 2009; Low \& Bordia, 2011) occurrence in today's organizations. If this is the case, then organizations should be foremost concerned with understanding the organizational circumstances and employee characteristics that are likely to minimize or aggravate employee responses to breach.

In this article, we examine the interaction of both contextual factors (i.e., perceived aggressive culture) and dispositional characteristics (i.e., employee self-control) in the psychological contract dynamics predicting workplace deviance. To do this, we build on the work of Bordia and colleagues (2008), who argued and empirically demonstrated that (1) psychological contract breach results in affective reactions of anger and frustration (referred to as psychological contract violation); (2) psychological contract violation results in a desire for revenge, which serves as a motivational force and drives workplace deviance; and (3) self-control, or the degree to which individuals are able to exert effortful control over their emotions and impulses (Baumeister, Heatherton, \& Tice, 1994), moderates the revenge cognitions-deviant behavior relationship. In this research, we extend Bordia and colleagues' previous research by proposing that perceived aggressive work culture - in which employees are encouraged to be competitive, confrontational, and negative (Cooke \& Szumal, 1987; Douglas \& Martinko, 2001) — will exacerbate the strength of (1) the psychological contract breach-psychological contract violation-revenge cognitions relationship and (2) the psychological contract violation-revenge cognitions-workplace deviance relationship. We further explore the role that employee self-control plays in mitigating these relationships, with the expectation that employees with high levels of self-control will be less likely to 
experience negative emotions, develop a desire for revenge, and engage in deviant acts, even when they perceive a highly aggressive culture.

The research reported here builds on previous work on the relationship between psychological contract breach and workplace deviance in three important ways. First, we expand the body of research on psychological contracts in general and the work of Bordia and colleagues (2008) specifically by investigating the role that organizational context plays in either aggravating or inhibiting employee responses to breach. Indeed, organizational research on social exchange phenomena in general (Zagenczyk, Restubog, Kiewitz, Kiazad, \& Tang, in press; Zagenczyk, Scott, Gibney, Murrell, \& Thatcher, 2010) and responses to psychological contract breach in particular (Bordia, Restubog, Bordia, \& Tang, 2010; Kiewitz et al., 2009; Restubog, Hornsey, Bordia, \& Esposo, 2008; Turnley, Bolino, Lester, \& Bloodgood, 2003) has largely ignored the organizational context, despite numerous calls for research in this area (Emerson, 1976). We integrate both social information processing theory (Salancik \& Pfeffer, 1978) and social learning theory (Bandura, 1986) to argue that a perceived aggressive work culture will shape the psychological contract dynamics.

Second, given that psychological contracts are based on idiosyncratic beliefs (Rousseau, 1995), understanding the influence of self-control in the psychological contract process is warranted because it may mitigate the individual's negative affective, cognitive, and behavioral responses to breach. Self-control is relevant because it may be used as a means to reframe hostile interpretations with less hostile ones; it may divert the individual from engaging in hostile affective reactions; and it can restrain the enactment of anger (Denson, DeWall, \& Finkel, in press; Gottfredson \& Hirschi, 1990). Thus, our research contributes to the psychological contract literature by testing the independent interactive effects as well as the combined interactive effects of self-control and perceived aggressive work culture in each stage of our model. We test our hypotheses in two independent samples of hospitality employees in Australia and the Philippines. In the sections that follow, we develop the theoretical rationale for the predicted relationships.

\section{Theoretical Background and Hypotheses}

\section{Relationships Among Psychological Contract Breach, Psychological Contract Violation Revenge Cognitions, and Workplace Deviance}

Researchers have theoretically and empirically distinguished between an employee's recognition that the organization has not fulfilled its obligations (i.e., psychological contract breach) and the "affective and emotional experience of disappointment, frustration, and anger" (i.e., psychological contract violation; Morrison \& Robinson, 1997: 228) that arises from the employee's cognitive assessment of breach (Morrison \& Robinson, 1997; Robinson \& Morrison, 2000). Morrison and Robinson's (1997) conceptual model and affective events theory (Weiss \& Cropanzano, 1996) account for how emotions may function as a mediating mechanism between certain events within the work environment and employee responses (such as revenge). Consistent with Bordia and colleagues (2008), we argue that breach is 
viewed as an affective event that will cause employees to experience an emotionally charged affective reaction (e.g., violation; see Weiss \& Cropanzano, 1996).

According to the thermodynamic model of revenge (Bies, Tripp, \& Kramer, 1997), psychological contract violation should lead to revenge cognitions. This model suggests that revenge unfolds in several phases: (1) provocations in the workplace, such as psychological contract breach, serve as a triggering mechanism for revenge (Aquino, Tripp, \& Bies, 2006); (2) such events are likely to result in perceptions of inequity and eventually a "deeper and more intense response, akin to anger and moral outrage" (Rousseau, 1989: 128), which leads to thoughts of revenge (Bies et al., 1997); (3) this is followed by the "reaction phase" in which individuals may respond by choosing to forgive, to forget, or to engage in deviant behaviors in order to seek revenge or relieve frustration (Bordia et al., 2008; Robinson \& Bennett, 1995). Based on these theoretical and empirical considerations, we replicate the mediation model initially proposed and tested by Bordia and colleagues (2008). In the next section, we extend Bordia and colleagues' mediation model by examining the moderating roles of self-control and perceptions of exposure to aggressive culture within each stage of the model.

\section{Self-Control and Perceived Aggressive Culture as Moderators}

The extent to which employees feel violated, and thus engage in revenge-seeking thoughts and aggressive acts, is likely to be influenced by contextual (e.g., social environment) and dispositional factors (Bies et al., 1997; Douglas \& Martinko, 2001). In this section, we discuss the role of self-control (a personality variable) and perceived aggressive culture (a situational variable) as moderators within the psychological contract breach dynamics resulting in workplace deviance.

Defined as "freedom from impulsivity" (Sarchione, Cuttler, Muchinsky, \& Nelson-Gray, 1998: 905), self-control refers to exerting control over one's thoughts (e.g., by suppressing negative thoughts), emotions (e.g., containing or changing emotions), and behaviors (e.g., curbing or modifying behaviors; Muraven \& Baumeister, 2000). Individuals activate their self-control when they exert effort to restrain or regulate both their internal and external responses. Self-control is positively associated with academic achievement, psychological well-being (e.g., low levels of depression and anxiety), self-esteem, and productive interpersonal relationships (Tangney, Baumeister, \& Boone, 2004) and is negatively related to dysfunctional behaviors (Sarchione et al., 1998).

We draw on Gottfredson and Hirschi's (1990) general theory of crime to advance the argument that self-control will moderate the breach-violation-revenge cognitions relationship. The core tenet of the general theory of crime is that individuals with low levels of self-control are more likely to respond to situational triggers with criminal acts when given the opportunity to do so. Individuals with low levels of self-control are likely to succumb to instigating factors and commit crimes; they have difficulty predicting the future consequences of their thoughts and actions. Accordingly, we propose that a high level of self-control enables employees to curb their anger reactions when faced with a potentially emotion-provoking situation such as psychological contract breach. Similarly, we would 
expect that high levels of self-control could positively energize employees' coping activity when dealing with psychological contract violation. Affective reactions such as feelings of anger, disappointment, and betrayal are likely to fuel and instigate thoughts of revenge. Employees with high levels of self-control are more likely to regulate their thought processes (i.e., revenge cognitions) that emerge after an episode of anger experience (i.e., psychological contract violation). To this end, Brown, Westbrook, and Challagalla (2005) found that selfcontrol mitigated the effects of negative emotions on performance. Formally, we predict:

Hypothesis 1: The conditional indirect effects of psychological contract breach in predicting revenge cognitions via psychological contract violation will be stronger for those employees with low as opposed to high self-control.

We would also expect that the conditional indirect effects of psychological contract violation in predicting workplace deviance via revenge cognitions will be stronger for those employees with low as opposed to high levels of self-control. Individuals with low selfcontrol, as opposed to those with high self-control, are characterized as self-centered, impulsive, short-tempered, and insensitive to the pain and suffering of others (Gottfredson \& Hirschi, 1990). They also have lower thresholds for managing frustration and prefer immediate gratification. Given these characteristics, employees with low levels of selfcontrol who experience psychological contract violation will find it difficult to disconnect from their desire for revenge seeking. Unable to control these impulses, these revenge cognitions will translate into deviant behaviors. In contrast, individuals with high selfcontrol will successfully inhibit these impulses to act in a deviant manner in response to revenge cognitions. Thus, we predict:

Hypothesis 2: The conditional indirect effects of psychological contract violation in predicting workplace deviance via revenge cognitions will be stronger for those employees with low as opposed to high self-control.

In this study, we also test the role of perceived aggressive work culture as a moderator variable in the psychological contract dynamics. Perceived aggressive work culture refers to an individual's perception that the organization encourages its employees to be competitive, confrontational, and negative (Cooke \& Szumal, 1987; Douglas \& Martinko, 2001). We draw on social information processing theory (Salancik \& Pfeffer, 1978) to propose that employees will experience violation (in response to breach), develop revenge cognitions (as a result of violation), and behave in accordance with revenge cognitions by engaging in deviant behaviors when they perceive a highly aggressive culture.

Social information processing theory (Salancik \& Pfeffer, 1978) suggests that to make sense of their environments, individuals attend to social information that shapes their attitudes, behaviors, and beliefs. Social information is influential because it guides employees' attention toward or away from aspects of the work environment and provides access to coworkers' and supervisors' interpretations of events in organizations, which helps to give meaning to employees (Salancik \& Pfeffer, 1978). Few studies have explored the role that the organizational context plays in shaping employee responses to psychological 
contract breach. One such effort by Kiewitz and colleagues (2009) demonstrated that employees had lower perceptions of organizational support in response to psychological contract breach when organizational politics were high as opposed to low. These authors suggested that politics represents a "broad, brushstroke attribution" (Kiewitz et al., 2009: 817 ) for the overall malevolent intent of the organization. In this research, we expect that perceived aggressive work culture will make employees less likely to give the organization the benefit of the doubt for breach. As a result, employees will be more apt to experience psychological contract violation and engage in revenge-seeking thoughts in response to psychological contract breach.

Hypothesis 3: The conditional indirect effects of psychological contract breach in predicting revenge cognitions via psychological contract violation will be stronger for those employees with high as opposed to low perceived aggressive work culture.

Building on social information processing theory, Bandura's (1986) articulation of social learning theory proposes that individuals observe the behaviors, attitudes, and emotional reactions of others to understand what behaviors are acceptable in a given setting. Social learning is particularly salient when aggressive behavior is considered (Bandura, 1986). With respect to aggression, scholars have theorized that hostile work environments essentially legitimize aggressive behavior (Robinson \& O'Leary-Kelly, 1998) through processes described in social learning theory. Thus, social learning has been used to explain how living in an aggressive neighborhood results in aggression in the home (Berkowitz, 1993) as well as to link aggressive behavior at home with aggressive behavior in the workplace (Douglas \& Martinko, 2001). Robinson and O'Leary-Kelly (1998) hypothesized and found support for the notion that employees tended to engage in antisocial behavior in the workplace to a greater degree when members of their workgroup made such behavior common. Likewise, a study by Aquino, Douglas, and Martinko (2004) showed that employees who observed aggressive role models tended to engage in higher levels of aggressive behaviors themselves. Overall, the rationale proposed by both social learning and social information processing theories suggests that the extent to which one perceives an aggressive culture will be an important determinant of whether employees will ruminate and act on revenge cognitions that they experience. Thus, we offer the following hypothesis:

Hypothesis 4: The conditional indirect effects of psychological contract violation in predicting workplace deviance via revenge cognitions will be stronger for those employees with high as opposed to low perceived aggressive work culture.

In addition to the independent moderator effects, we draw on Folger and Skarlicki's (1998) popcorn metaphor of employee aggression to further hypothesize that the interaction between self-control and perceived aggressive work culture will influence the indirect effect relationships among (a) psychological contract breach in predicting revenge cognitions via psychological contract violation and (b) psychological contract violation in predicting workplace deviance via revenge cognitions. Folger and Skarlicki argued that the heat where the popcorn is cooked represents situations within organizations, while the kernels represent 
the individuals in the workplace. As the heat continues to increase, kernels will pop. However, the researchers reasoned that each kernel may take a different period of time to pop because of each one's unique individual characteristics. Thus, the popcorn metaphor draws attention to person-situation interaction in predicting aggressive behaviors at work.

Informed by this approach, we propose that the degree to which employees consider revenge resulting from psychological contract breach and psychological contract violation will be contingent upon their self-control and the degree to which the culture is perceived to be aggressive. Employees unable to regulate their emotions - that is, those with low levels of self-control - are more likely to feel enraged by perceptions of breach. Similarly, the perceptions of aggressive culture may further contribute to their feelings of violation. Thus, when employees perceive that they are in a highly aggressive culture, low self-control employees are more likely to feel violated and engage in vengeful thoughts. In contrast, employees with high levels of self-control will better manage their negative emotions even when they perceive that they are in a highly aggressive culture.

Hypothesis 5: At high levels of perceived aggressive work culture, the conditional indirect effects of psychological contract breach in predicting revenge cognitions via psychological contract violation will be stronger for those employees with low as opposed to high self-control.

Finally, we expect that employees may be more or less likely to engage in acts consistent with their desire for revenge, depending on their levels of self-control and whether the situational context affords them the opportunity. This notion is supported by the general theory of crime (Gottfredson \& Hirschi, 1990) in which it is postulated that low self-control individuals tend to be uninhibited and act on opportunities to commit aggressive acts but do not necessarily instigate these behaviors especially in the presence of situational obstacles and constraints. Indeed, Grasmick, Tittle, Bursik, and Arneklev noted, "In the presence of an opportunity to commit a crime, individuals with low self-control are likely to commit it whereas individuals with high self-control are not. Crime, then is an interactive function of self-control and crime opportunity" (1993: 10). In the context of our study, an individual with a low level of self-control ruminating about revenge as a result of his or her anger toward the organization is likely to engage in deviant behaviors if the organizational environment (e.g., perceptions of high aggressive culture) provides such an opportunity to engage in such behaviors.

Hypothesis 6: At high levels of perceived aggressive work culture, the conditional indirect effects of psychological contract violation in predicting workplace deviance via revenge cognitions will be stronger for those employees with low as opposed to high self-control.

\section{Method}

\section{Participants and Procedure}

Sample 1. Four undergraduate research assistants approached approximately 220 hospitality workers who worked at restaurants in and around the large metropolitan areas of 
Sydney, Melbourne, and Brisbane, Australia. Participants who consented were requested to complete a brief survey, yielding a response rate of $66.36 \%(N=146)$. Each brief survey kit was collected three to seven days after administration, allowing the workers to complete the questionnaire at a suitable time in order to minimize work disruption and maximize the response rate. The survey kit comprised an information sheet (stating the aims of the study, confidentiality, voluntariness of participation, and signed consent), self-report questionnaire, peer rating form, debriefing sheet, and a small chocolate as an incentive for participation. These items were enclosed in a large envelope to ensure the anonymity of participants' responses. In addition, one coworker of each of these employees received a peer rating form. We received 146 completed peer rating surveys.

Of the 146 participants, $52 \%$ were female, and the majority (64.4\%) was between 21 and 30 years of age. Participants had an average of 5 years of experience in the hospitality industry and had been employed in their current jobs for an average of 14 months. Participants were predominantly food and beverage attendants. The majority had no university qualification (82.9\%). Participants worked for a minimum of 25 hours per week. Fifty-one percent of the participants worked on a part-time basis.

Sample 2. The survey questionnaires were administered to 300 hospitality workers in the Philippines who were taking seminar courses on restaurant customer service; sanitation, safety, and hygiene; table setting; and food preparation. All participants were working fulltime in customer service. Survey questionnaires were administered to the participants in two phases, approximately four weeks apart. In Phase 1 we measured predictor variables, whereas in Phase 2 we measured the outcome variable (i.e., workplace deviance). We separated the measures of predictor and criterion variables to minimize the effects of common method variance (Podsakoff \& Organ, 1986). The questionnaires were prepared in English because it is spoken by a vast majority of the Filipino population (Bernardo, 2004).

In the first administration of the survey, measures of global perceptions of breach, revenge cognitions, aggressive work culture, self-control, and demographic variables were included. We received a total of 237 out of the 300 questionnaires distributed (response rate of $79 \%$ ). Four weeks after, a second survey assessing the outcome variable (i.e., workplace deviance) was administered to the 237 participants. Of this number, 199 replied, yielding a response rate of $83.97 \%$ for the second wave of data collection. The questionnaires obtained from 31 participants were removed because they either failed to provide the same anonymous code for both administrations or failed to complete the questionnaires. Thus, a total of 168 participants who completed both questionnaires comprised the final sample. Of the 168 participants, $57.7 \%$ were male, and the average age of the participants was 28.78 years. The majority $(67.3 \%)$ of the participants had been employed in their current organizations for between 1 and 3 years.

\section{Measures}

Unless otherwise specified, the response format for all items, excluding the demographic variables, was a 7-point Likert-type scale $(1=$ strongly disagree to $7=$ strongly agree $)$, with 
items coded such that a higher score indicated a greater amount of the focal construct (except for when reverse-coded items were considered). The phrasing of some items was adjusted to befit the colloquialisms of the hospitality industry.

Perceived global psychological contract breach. A five-item global measure of breach created by Robinson and Morrison (2000) was used to assess the extent to which employees perceived that their psychological contracts had been fulfilled by their organizations. Measuring perceived contract breach as a global perception captures employees' overall perceptions of how well the organization has delivered the promised obligations to its employees (Robinson \& Morrison, 2000). Example items include "Almost all the promises made to me by my employer during recruitment have been kept so far" (reverse coded) and "I have not received everything promised to me in exchange for my contributions." This scale yielded a reliability coefficient of .96 for Sample 1 and .71 for Sample 2. Peer-rated psychological contract breach was also used in Sample 1 to validate employee reports of psychological contract breach. It was assessed using a single item measure: "Overall, I believe that my employer has done an excellent job of fulfilling its promises/commitments made to this person" (reverse coded). The item regarding breach of psychological contract is similar to questions used in previous research to determine whether or not employees had experienced contract breach (Robinson \& Rousseau, 1994).

Psychological contract violation. Psychological contract violation was assessed using the four-item scale developed by Robinson and Morrison (2000). An example item is "I feel a great deal of anger towards my organization.” The scale reliability was .96 for both Samples 1 and 2.

Revenge cognitions. We assessed revenge cognitions using the five-item scale developed by Bradfield and Aquino (1999). An example item is "I thought of something to get even with my organization." The scale reliabilities were .93 and .92 for Sample 1 and Sample 2, respectively.

Perceived aggressive work culture. This variable was measured via a four-item scale based on the scale developed by Douglas and Martinko (2001). The items were modified slightly because these authors sought to determine the extent to which norms outside the workplace were aggressive and we were interested in understanding workplace norms. An example item is "In this restaurant, employees were often engaged in verbal confrontations." The scale reliabilities were .93 and .87 for Sample 1 and Sample 2, respectively.

Self-control. Self-control was assessed using the 10-item scale developed by Scott (1965). An example item is "I reply to anger with gentleness." Scale reliability for Sample 1 was 95. Due to the length of the self-control measure and the work constraints imposed on the participants in Sample 2, we used a 4-item short measure of Time 1 self-control $(\alpha=.88)$. To provide evidence that the shortened measure of self-control was equivalent to the full measure, we administered the full measure to an independent sample of 94 government employees. Bivariate correlations indicate that the shortened and complete versions were highly correlated, $r=.81, p<.001$. 
Workplace deviance. We used a critical incident technique (Flanagan, 1954) to develop a measure of deviance that includes specific incidents of deviant behaviors that are relevant for hospitality employees. To do this, we conducted interviews with three restaurant managers who were identified as subject matter experts, given their substantial experience in the hospitality industry (i.e., more than 10 years of managing restaurants). Using a critical incident technique (Flanagan, 1954), we asked the subject matter experts to reflect on specific incidents or behaviors their service employees (e.g., waiter, waitress, bar person) engaged in during the past three months that were regarded as deviant in nature and their justification for considering this behavior as an example of deviant behavior. Each subject matter expert provided three to four examples for a total of 10 behavioral exemplars. Using a consensual approach, we reduced the number of behavioral exemplars based on the principle that each behavioral exemplar should be directly observable by one's coworker (items were reduced from 10 to 5). Peers were asked to report the extent to which their coworkers engaged in such behaviors. Example items include "This person stole restaurant's resources (e.g., food, drinks, etc.)," "This person misused discount privilege," and "This person gave food or drinks at discounted prices." The scale reliabilities were .92 and .96 for the peer-rated measure in Sample 1 and self-reported measure in Sample 2, respectively.

Control variables. Consistent with past research on psychological contracts and workplace deviance, we controlled for the effects of gender, age, employment status, and tenure (Bradfield \& Aquino, 1999). Gender (male $=0$ and female $=1$ ) was controlled because research suggests that males tend to be more aggressive than females and have higher levels of revenge attitudes than females do (Aquino et al., 2006). Age (in years) was controlled because the social psychological literature suggests that it is related to the incidence of workplace aggression (e.g., Geen, 1990). Tenure was controlled because there is evidence to suggest that it is associated with antisocial behavior at work (Robinson \& O'Leary-Kelly, 1998). We controlled for employment status because part-time employees tend to perceive that their exchange relationships are more economic in nature, while fulltime employees report greater relational and transactional psychological contract obligations to their employers (Gakovic \& Tetrick, 2003). Education was controlled because sociological research suggests that lack of education is often associated with the propensity to engage in criminal activities (Campbell \& Muncer, 1990). Given that self-report measures of workplace deviant behaviors and revenge cognitions are vulnerable to self-report bias, we controlled for the effects of social desirability using the short version of the CrowneMarlowe Social Desirability Scale (Strahan \& Gerbasi, 1972). The scale, which consists of 10 true-false items describing desirable and undesirable behaviors, is used to determine the extent to which test scores have been influenced by the individual's desire to present a positive image of his or her character. This scale yielded a reliability coefficient of .74.

\section{Results}

Descriptive statistics, zero-order correlations, and reliability coefficients are presented in Table 1. To validate employee perceptions of psychological contract breach in Sample 1, 


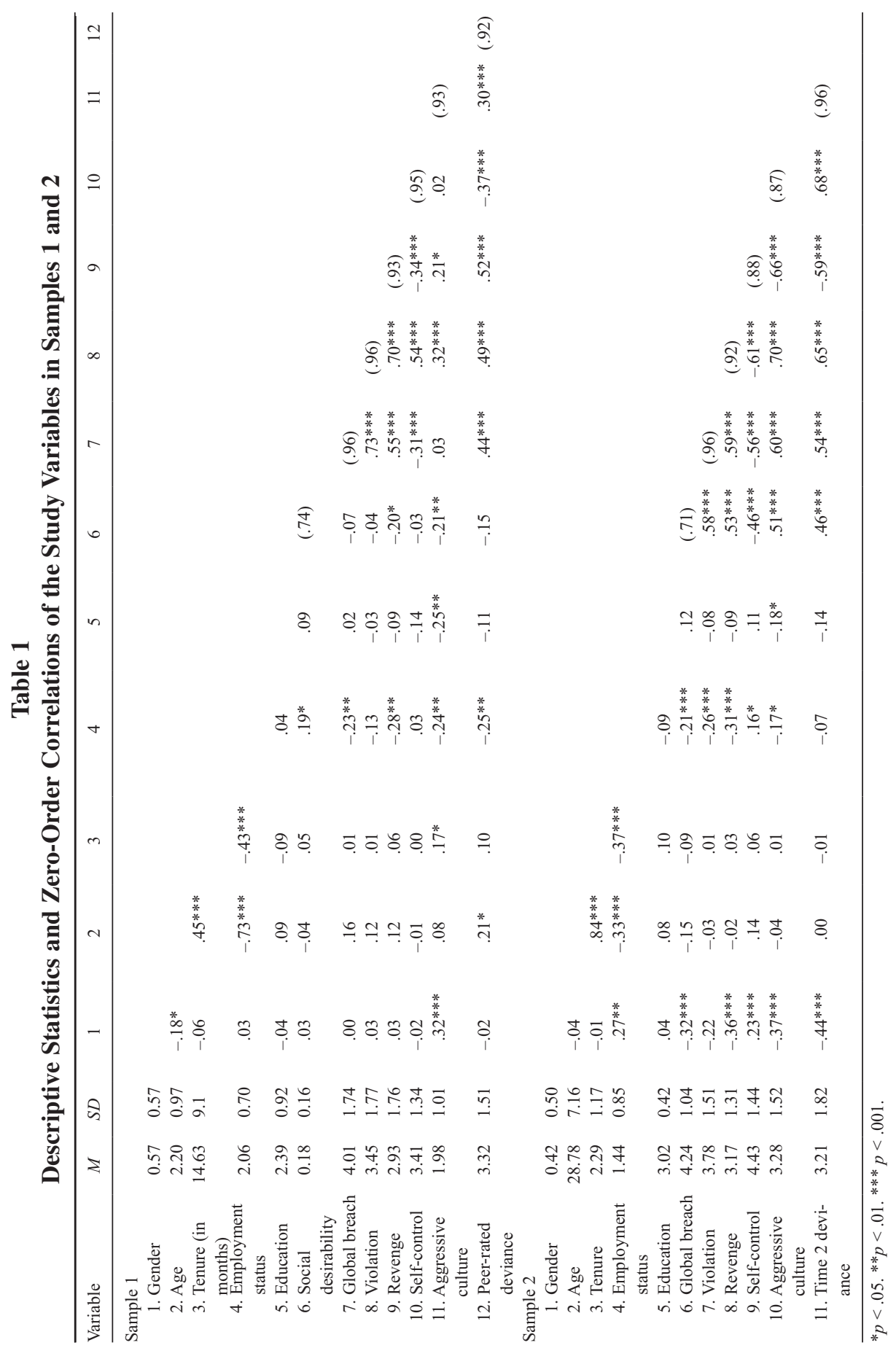


Table 2

Path Analytic Results: Indirect Effects at Low and High Levels of the Relevant Moderator in Samples 1 and 2

\begin{tabular}{|c|c|c|c|c|c|c|c|c|}
\hline & \multicolumn{4}{|c|}{ Sample 1} & \multicolumn{4}{|c|}{ Sample 2} \\
\hline & IE & $S E$ & $z$ & $\mathrm{CI}$ & IE & $S E$ & $z$ & $\mathrm{CI}$ \\
\hline \multicolumn{9}{|l|}{ Hypothesis 1} \\
\hline \multicolumn{9}{|l|}{ First-stage moderation } \\
\hline $\begin{array}{l}\text { Simple paths for low } \\
\text { self-control }\end{array}$ & .10 & .04 & 0.85 & -.09 to .14 & .02 & .03 & 0.84 & -.12 to .03 \\
\hline $\begin{array}{l}\text { Simple paths for high } \\
\text { self-control }\end{array}$ & .08 & .05 & 1.07 & -.05 to .11 & .05 & .03 & 1.47 & -.01 to .13 \\
\hline \multicolumn{9}{|l|}{ Second-stage moderation } \\
\hline $\begin{array}{l}\text { Simple paths for low } \\
\text { self-control }\end{array}$ & .05 & .03 & 0.90 & -.06 to .17 & .06 & .04 & 1.58 & -.03 to .24 \\
\hline $\begin{array}{l}\text { Simple paths for high } \\
\text { self-control }\end{array}$ & .04 & .04 & 0.68 & -.08 to .12 & .09 & .05 & 1.26 & -.02 to .19 \\
\hline \multicolumn{9}{|l|}{ Hypothesis 2} \\
\hline \multicolumn{9}{|l|}{ First-stage moderation } \\
\hline $\begin{array}{l}\text { Simple paths for low } \\
\text { self-control }\end{array}$ & .09 & .07 & 1.21 & -.06 to .28 & .11 & .06 & 1.77 & -.04 to .28 \\
\hline $\begin{array}{l}\text { Simple paths for high } \\
\text { self-control }\end{array}$ & .09 & .07 & 1.20 & -.06 to .27 & .06 & .05 & 1.53 & -.05 to .26 \\
\hline \multicolumn{9}{|l|}{ Second-stage moderation } \\
\hline $\begin{array}{l}\text { Simple paths for low } \\
\text { self-control }\end{array}$ & -.02 & .12 & -0.19 & -.16 to .25 & .08 & .10 & 0.85 & -.12 to .19 \\
\hline $\begin{array}{l}\text { Simple paths for high } \\
\text { self-control }\end{array}$ & .14 & .09 & 1.58 & -.04 to .35 & .12 & .09 & 1.54 & -.07 to .21 \\
\hline \multicolumn{9}{|l|}{ Hypothesis 3} \\
\hline \multicolumn{9}{|l|}{ First-stage moderation } \\
\hline $\begin{array}{l}\text { Simple paths for low } \\
\text { aggressive culture }\end{array}$ & -.02 & .04 & 0.90 & -.01 to .15 & .03 & .02 & 1.15 & -.01 to .10 \\
\hline $\begin{array}{l}\text { Simple paths for high } \\
\text { aggressive culture }\end{array}$ & .06 & .06 & 1.01 & -.13 to .10 & .04 & .03 & 1.26 & -.11 to .03 \\
\hline \multicolumn{9}{|l|}{ Second-stage moderation } \\
\hline $\begin{array}{c}\text { Simple paths for low } \\
\text { aggressive culture }\end{array}$ & .01 & .03 & 0.74 & -.01 to .16 & .05 & .03 & 1.64 & -.01 to .14 \\
\hline $\begin{array}{l}\text { Simple paths for high } \\
\text { aggressive culture }\end{array}$ & .09 & .03 & 0.84 & -.04 to .12 & .01 & .03 & 0.50 & -.06 to .11 \\
\hline \multicolumn{9}{|l|}{ Hypothesis 4} \\
\hline \multicolumn{9}{|l|}{ First-stage moderation } \\
\hline $\begin{array}{l}\text { Simple paths for low } \\
\text { aggressive culture }\end{array}$ & .13 & .07 & 1.69 & -.02 to .30 & .10 & .03 & 1.70 & -.06 to .30 \\
\hline $\begin{array}{l}\text { Simple paths for high } \\
\text { aggressive culture }\end{array}$ & .13 & .07 & 1.70 & -.01 to .31 & .02 & .03 & 0.51 & -.05 to .13 \\
\hline
\end{tabular}


Table 2 (continued)

\begin{tabular}{|c|c|c|c|c|c|c|c|c|}
\hline & \multicolumn{4}{|c|}{ Sample 1} & \multicolumn{4}{|c|}{ Sample 2} \\
\hline & $\mathrm{IE}$ & $S E$ & $z$ & $\mathrm{CI}$ & IE & $S E$ & $z$ & $\mathrm{CI}$ \\
\hline \multicolumn{9}{|l|}{ Second-stage moderation } \\
\hline $\begin{array}{l}\text { Simple paths for low } \\
\text { aggressive culture }\end{array}$ & .08 & .07 & 0.94 & -.12 to .25 & .08 & .10 & 0.85 & -.12 to .19 \\
\hline $\begin{array}{c}\text { Simple paths for high } \\
\text { aggressive culture }\end{array}$ & .21 & .09 & 2.35 & .05 to .38 & .12 & .09 & 1.54 & -.07 to .21 \\
\hline \multicolumn{9}{|l|}{ Hypothesis 5} \\
\hline \multicolumn{9}{|l|}{ First-stage moderation } \\
\hline $\begin{array}{l}\text { Simple paths for low } \\
\text { self-control and low } \\
\text { aggressive culture }\end{array}$ & .05 & .04 & 0.73 & -.04 to .15 & .00 & .02 & 0.00 & -.05 to .08 \\
\hline $\begin{array}{l}\text { Simple paths for low } \\
\text { self-control and high } \\
\text { aggressive culture }\end{array}$ & .09 & .04 & 1.16 & -.06 to .13 & .00 & .03 & 0.12 & -.05 to .09 \\
\hline $\begin{array}{l}\text { Simple paths for high } \\
\text { self-control and low } \\
\text { aggressive culture }\end{array}$ & .12 & .08 & 1.50 & -.03 to .14 & .04 & .05 & 0.77 & -.07 to .14 \\
\hline $\begin{array}{l}\text { Simple paths for high } \\
\text { self-control and high } \\
\text { aggressive culture }\end{array}$ & .04 & .05 & 0.76 & -.08 to .11 & .00 & .05 & 0.08 & -.08 to .07 \\
\hline \multicolumn{9}{|l|}{ Second-stage moderation } \\
\hline $\begin{array}{l}\text { Simple paths for low } \\
\text { self-control and low } \\
\text { aggressive culture }\end{array}$ & .08 & .02 & 0.99 & -.02 to .16 & .03 & .04 & 0.84 & -.02 to .16 \\
\hline $\begin{array}{l}\text { Simple paths for low } \\
\text { self-control and high } \\
\text { aggressive culture }\end{array}$ & .09 & .03 & 1.07 & -.17 to .03 & -.04 & .05 & 0.87 & -.17 to .03 \\
\hline $\begin{array}{l}\text { Simple paths for high } \\
\text { self-control and low } \\
\text { aggressive culture }\end{array}$ & .16 & .19 & 0.96 & -.01 to .18 & .07 & .05 & 1.51 & -.01 to .18 \\
\hline $\begin{array}{l}\text { Simple paths for high } \\
\text { self-control and high } \\
\text { aggressive culture }\end{array}$ & .18 & .16 & 1.22 & -.01 to .16 & .05 & .04 & 1.34 & -.01 to .16 \\
\hline \multicolumn{9}{|l|}{ Hypothesis 6} \\
\hline \multicolumn{9}{|l|}{ First-stage moderation } \\
\hline $\begin{array}{l}\text { Simple paths for low } \\
\text { self-control and low } \\
\text { aggressive culture }\end{array}$ & .21 & .12 & 1.72 & -.04 to .53 & .05 & .04 & 1.25 & -.01 to .22 \\
\hline $\begin{array}{l}\text { Simple paths for low } \\
\text { self-control and high } \\
\text { aggressive culture }\end{array}$ & .26 & .15 & 1.80 & -.03 to .66 & -.06 & .06 & 1.33 & -.22 to .01 \\
\hline $\begin{array}{l}\text { Simple paths for high } \\
\text { self-control and low } \\
\text { aggressive culture }\end{array}$ & .03 & .11 & 0.30 & -.22 to .35 & .10 & .06 & 1.78 & -.01 to .27 \\
\hline
\end{tabular}


Table 2 (continued)

\begin{tabular}{|c|c|c|c|c|c|c|c|c|}
\hline & \multicolumn{4}{|c|}{ Sample 1} & \multicolumn{4}{|c|}{ Sample 2} \\
\hline & IE & $S E$ & $z$ & CI & IE & $S E$ & $z$ & $\mathrm{CI}$ \\
\hline $\begin{array}{l}\text { Simple paths for high } \\
\text { self-control and high } \\
\text { aggressive culture } \\
\text { Second-stage moderation }\end{array}$ & .02 & .08 & 0.29 & -.15 to .39 & .09 & .05 & 1.82 & -.02 to .23 \\
\hline $\begin{array}{l}\text { Simple paths for low } \\
\text { self-control and low } \\
\text { aggressive culture }\end{array}$ & .14 & .16 & 0.87 & -.06 to .44 & .11 & .06 & 1.70 & -.03 to .41 \\
\hline $\begin{array}{l}\text { Simple paths for low } \\
\text { self-control and high } \\
\text { aggressive culture }\end{array}$ & .39 & .14 & 2.73 & .08 to .68 & .15 & .07 & 2.03 & .01 to .34 \\
\hline $\begin{array}{l}\text { Simple paths for high } \\
\text { self-control and low } \\
\text { aggressive culture }\end{array}$ & .02 & .11 & 0.21 & -.23 to .37 & -.10 & .08 & 1.34 & -.33 to .02 \\
\hline $\begin{array}{l}\text { Simple paths for high } \\
\text { self-control and high } \\
\text { aggressive culture }\end{array}$ & .05 & .15 & 0.31 & -.27 to .33 & .08 & .06 & 0.75 & -.05 to .30 \\
\hline
\end{tabular}

Note $:$ IE $=$ indirect effect; $S E=$ standard error; $\mathrm{CI}=$ confidence interval.

coworker ratings of psychological contract breach were measured. Results indicated that self-rated breach perceptions and peer-rated perceptions of breach were moderately correlated, $r(132)=.44, p<.001$. To test our hypothesized predictions, we used Preacher, Rucker, and Hayes's (2007) moderated mediation macro to test the conditional indirect effects at various levels of the moderator within the psychological contract process. Control variables were included in all analyses. Indirect effects and confidence intervals (CIs) are reported in Table 2.

Hypothesis 1 proposed that conditional indirect effects of psychological contract breach in predicting revenge cognitions via psychological contract violation would be stronger for those employees with low as opposed to high self-control. To test this, we examined the first-stage and second-stage moderating effect of self-control within the breach-violationrevenge cognition relationship. Results revealed that the conditional indirect effects of breach on revenge cognitions through violation was not significant for Samples 1 and 2 at both low (Sample 1 first-stage moderation: indirect effect $=.10, S E=.04, z=0.85,95 \%$ CI: -.09 to .14 , $n s$; Sample 1 second-stage moderation: indirect effect $=.05, S E=.03, z=0.90,95 \%$ CI: -.06 to $.17, n s$; Sample 2 first-stage moderation: indirect effect $=.02, S E=.03, z=0.84,95 \% \mathrm{CI}$ : -.12 to $.03, n s$; Sample 2 second-stage moderation: indirect effect $=.06, S E=.04, z=1.58$, 95\% CI: -.03 to $.24, n s$ ) and high levels of self-control (Sample 1 first-stage moderation: indirect effect $=.08, S E=.05, z=1.07,95 \%$ CI: -.05 to $.11, n s$; Sample 1 second-stage moderation: indirect effect $=.04, S E=.04, z=0.68,95 \% \mathrm{CI}:-.08$ to .12 , $n s$; Sample 2 firststage moderation: indirect effect $=.05, S E=.03, z=1.47,95 \% \mathrm{CI}:-.01$ to .13 , $n s$; Sample 2 second-stage moderation: indirect effect $=.09, S E=.05, z=1.26,95 \% \mathrm{CI}:-.02$ to $.19, n s$ ). Bootstrapping analysis (corrected $95 \%$ CIs) was calculated to examine the significance of 
the indirect effects at both high and low levels of self-control. Given that the CIs included 0 , we can conclude that the moderating role of self-control does not have a significant impact on the mediated relationship among breach, violation, and revenge.

Hypothesis 2 proposed that the conditional indirect effects of psychological contract violation in predicting workplace deviance via revenge cognitions would be stronger for those employees with low as opposed to high self-control. We did not find support for this prediction at either low (Sample 1 first-stage moderation: indirect effect $=.09, S E=.07, z=$ $1.21,95 \%$ CI: -.06 to $.28, n s$; Sample 1 second-stage moderation: indirect effect $=-.02, S E=$ $.12, z=-0.19,95 \% \mathrm{CI}:-.16$ to $.25, n s$; Sample 2 first-stage moderation: indirect effect $=.11$, $S E=.06, z=1.77,95 \% \mathrm{CI}:-.04$ to $.28, n s$; Sample 2 second-stage moderation: indirect effect $=.08, S E=.10, z=0.85,95 \%$ CI: -.12 to $.19, n s)$ or high levels of self-control (Sample 1 first-stage moderation: indirect effect $=.09, S E=.07, z=1.20,95 \% \mathrm{CI}:-.06$ to $.27, n s$; Sample 1 second-stage moderation: indirect effect $=.14, S E=.09, z=1.58, \mathrm{CI}:-.04$ to .35 , $n s$; Sample 2 first-stage moderation: indirect effect $=.06, S E=.05, z=1.53,95 \%$ CI: -.05 to $.26, n s$; Sample 2 second-stage moderation: indirect effect $=.12, S E=.09, z=1.54,95 \%$ CI: -.07 to $.21, n s$ ).

Hypothesis 3 proposed that the conditional indirect effects of psychological contract breach in predicting revenge cognitions via psychological contract violation would be stronger for those employees with high as opposed to low perceived aggressive work culture. The moderated mediation effects were nonsignificant for Samples 1 and 2 at both low (Sample 1 first-stage moderation: indirect effect $=-.02, S E=.04, z=0.90, \mathrm{CI}:-.01$ to .15 , $n s$; Sample 1 second-stage moderation: indirect effect $=.01, S E=.03, z=0.74$, CI: -.01 to $.16, n s$; Sample 2 first-stage moderation: indirect effect $=.03, S E=.02, z=1.15, \mathrm{CI}:-.01$ to $.10, n s$; Sample 2 second-stage moderation: indirect effect $=.05, S E=.03, z=1.64, \mathrm{CI}:-.01$ to $.14, n s$ ) and high levels of perceived aggressive work culture (Sample 1 first-stage moderation: indirect effect $=.06, S E=.06, z=1.01, \mathrm{CI}:-13$ to $.10, n s$; Sample 1 secondstage moderation: indirect effect $=.09, S E=.03, z=0.84, \mathrm{CI}:-.04$ to $.12, n s$; Sample 2 first-stage moderation: indirect effect $=-.04, S E=.03, z=1.26, \mathrm{CI}:-.11$ to $.03, n s$; Sample 2 second-stage moderation: indirect effect $=.01, S E=.03, z=0.50, \mathrm{CI}:-.06$ to $.11, n s$ ).

Hypothesis 4 proposed that the conditional indirect effects of psychological contract violation in predicting workplace deviance via revenge cognitions would be stronger for those employees with high as opposed to low aggressive work culture. Results suggest that the first-stage moderation effect was nonsignificant at both low (Sample 1 first-stage moderation: indirect effect $=.13, S E=.07, z=1.69, \mathrm{CI}:-.02$ to $.30, n s$; Sample 2 first-stage moderation: indirect effect $=.10, S E=.03, z=1.70, \mathrm{CI}:-.06$ to $.30, n s)$ and high levels of perceived aggressive work culture (Sample 1 first-stage moderation: indirect effect $=.13, S E=.07$, $z=1.70, \mathrm{CI}:-.01$ to $.31, n s$; Sample 2 first-stage moderation: indirect effect $=.02, S E=.03, z=$ $0.51, \mathrm{CI}:-.05$ to $.13, n s$ ) for both samples. However, our analysis suggests that the secondstage moderation was significant for Sample 1 but not for Sample 2 (see Table 2). That is, the conditional indirect effect for Sample 1 was significant for high (indirect effect $=.21, S E=$ $.09, z=2.35, p<.05$ ) but not for low (indirect effect $=.08, S E=.07, z=0.94, n s$ ) perceived aggressive work culture. The resulting CI for high perceived aggressive work culture ranged from .05 to .38 . Given that the range does not include 0 , we can conclude that these indirect effects were statistically significant. In contrast, the CI for low perceived aggressive work 
Figure 1

Interactive Effects Between Revenge Cognitions and Perceived Aggressive Work Culture in Predicting Peer-Rated Workplace Deviance in Sample 1

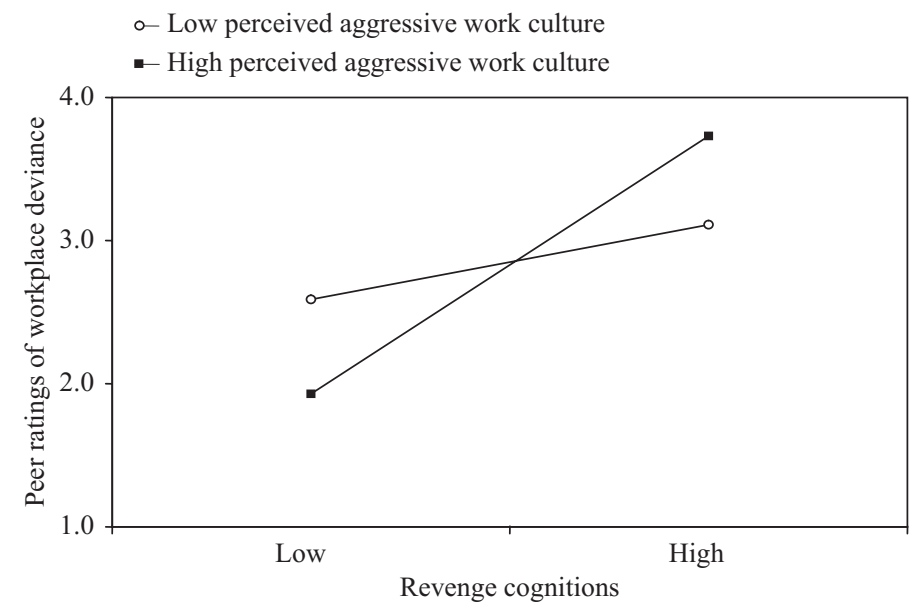

culture ranged from -.12 to .25 . Figure 1 shows that when employees perceive high levels of aggressive work culture, revenge cognitions were positively associated with workplace deviance, $\beta=.50, t(134)=-6.09, p<.001$. In contrast, when perceived aggressive work culture was low, there was a nonsignificant relationship between revenge cognitions and workplace deviance, $\beta=.17, t(134)=1.77$, ns. Overall, Hypothesis 4 was partially supported.

Hypothesis 5 proposed that at high levels of perceived aggressive work culture, the conditional indirect effects of psychological contract breach in predicting revenge cognitions via psychological contract violation would be stronger for those employees with low as opposed to high self-control. We performed the analysis on four combinations: (1) low selfcontrol and low aggressive culture, (2) low self-control and high aggressive culture, (3) high self-control and high aggressive culture, and (4) high self-control and low aggressive culture. None of these combinations were significant at first- and second-stage moderation for Samples 1 and 2 (see Table 2 for the results).

Hypothesis 6 proposed that at high levels of perceived aggressive work culture, the conditional indirect effects of psychological contract violation in predicting workplace deviance via revenge cognitions would be stronger for those employees with low as opposed to high self-control. Similar to Hypothesis 5, we performed the analysis on four combinations for first-stage moderation. No significant effects were found for (1) low self-control and low aggressive culture, (2) high self-control and high aggressive culture, and (3) high selfcontrol and low aggressive culture for Samples 1 and 2 (see Table 2 for results). Moreover, examining the second-stage moderation, with the exception of low self-control and high aggressive culture, no significant effects were found for (1) low self-control and low aggressive culture, (2) high self-control and high aggressive culture, and (3) high selfcontrol and low aggressive culture at first-stage moderation for Samples 1 and 2 (see Table 


\section{Figure 2}

\section{Three-Way Interactions Among Revenge Cognitions, Perceived Aggressive Work Culture, and Self-Control in Predicting Peer-Rated Workplace Deviance in Sample 1}

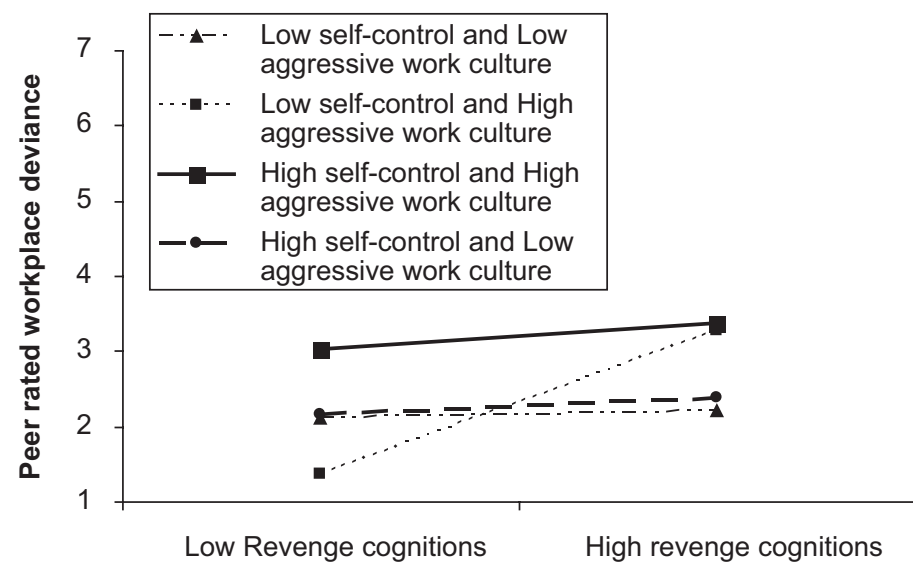

Revenge cognitions

2 for results). A closer inspection of the significant effects suggest that at low levels of selfcontrol, the conditional indirect effects of psychological contract violation in predicting workplace deviance through revenge cognitions was significant for high perceived aggressive work culture (Sample 1 second-stage moderation: indirect effect $=.39, S E=.14$, $z=2.73$, CI: .08 to $.68, p<.01$; Sample 2 indirect effect $=.15, S E=.07, z=2.03, \mathrm{CI}: .01$ to $.34, p<.05$ ), but not for low aggressive work culture (Sample 1 second-stage moderation: indirect effect $=.14, S E=.16, z=0.87, \mathrm{CI}:-.06$ to $.44, n s$; Sample 2 indirect effect $=.11$, $\mathrm{SE}=.06, z=1.70, \mathrm{CI}:-.03$ to $.41, n s)$. For Sample 1, as shown in Figure 2, simple slope analysis suggests that the effects of revenge cognitions on peer-rated deviance under conditions of low self-control and high perceived aggressive culture was statistically significant, $\beta=.39, t(138)=2.11, p<.05$. In contrast, the simple slopes representing other combinations were nonsignificant. As for Sample 2, as depicted in Figure 3, simple slope analysis suggests that the relationship between revenge cognitions and workplace deviance for those in high perceived aggressive work culture and low self-control was statistically significant, $\beta=.43, t(160)=1.99, p<.05$. Interestingly, we also found a significant positive relationship between revenge cognitions and deviance for those low in perceived aggressive culture and high in self-control, $\beta=.35, t(160)=2.5, p<.01$. The slopes representing other combinations were nonsignificant. Overall, Hypothesis 6 was partially supported.

\section{General Discussion}

In this article, we examined the interplay between psychological contract breach, psychological contract violation, revenge cognitions, self-control, perceived aggressive culture, and workplace deviance. Our results suggest that it is important to explore both 
Figure 3

Three-Way Interactions Among Revenge Cognitions, Perceived Aggressive Work Culture, and Self-Control in Predicting Time 2 Workplace Deviance in Sample 2

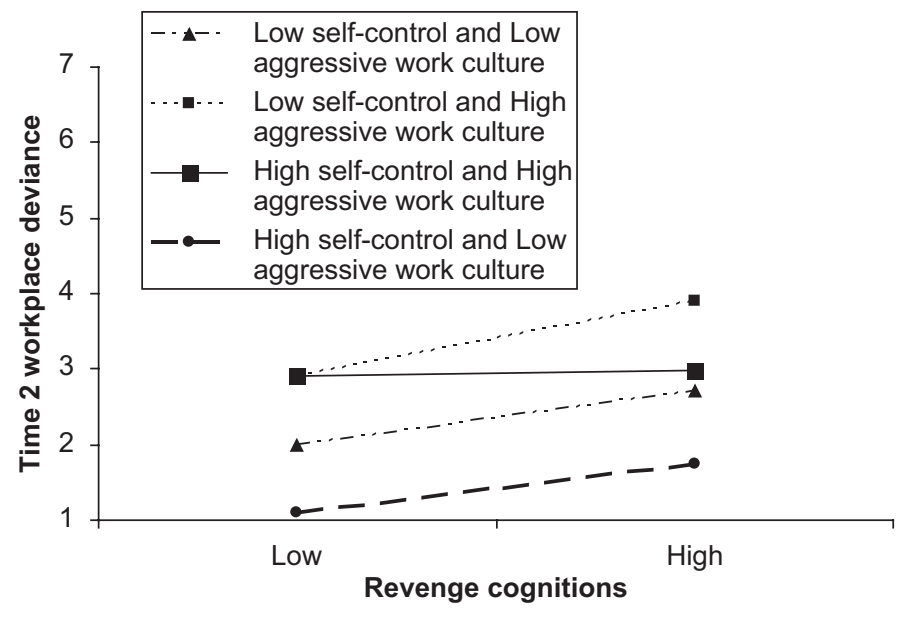

dispositional (self-control) and contextual (perceived aggressive culture) factors when considering whether and how employees will respond to psychological contract breach. In particular, the overall pattern of our results suggests that self-control and perceived aggressive culture influence whether or not employees will act on revenge cognitions, not whether employees experience violation in response to breach and then desire to seek revenge. Specifically, our results showed that employees were apt to act on revenge cognitions as a result of psychological contract violation and engage in deviance when they had low levels of self-control and perceived the cultures in which they worked to be aggressive.

Our research makes several important empirical and theoretical contributions. First, across the two samples, we did not find support for the first- and second-stage moderating effect of self-control within each stage of the model. One possible reason for the absence of support for these hypothesized relationships stems from the multifaceted nature of selfcontrol. Invoking a strength model of self-regulation, Baumeister and Heatherton (1996) provided some examples that could potentially explain self-regulation failure. For one, because self-regulation is a limited resource, it can be temporarily depleted. Overtiredness or exhaustion could potentially drain an individual's strength and therefore weaken one's self-control. Another example pertains to the notion of transcendence or the ability to focus one's awareness beyond the immediate stimuli. Individuals with high levels of transcendence are able to overcome their anger by looking beyond the immediate situation. That is, they can attempt to "let go" of their negative thoughts and emotions by reframing the event. These explanations raise further questions about the boundary conditions or efficacy of selfcontrol in restraining negative emotional, cognitive, and behavioral reactions. 
Second, we found support for Hypothesis 4 (second-stage moderation only) for Sample 1 only, which predicted that the conditional indirect effects of psychological contract violation in predicting workplace deviance via revenge cognitions will be stronger for those employees who perceived high as opposed to low aggressive work culture, but not for Hypothesis 3 (conditional indirect effects of perceived aggressive culture on the breach-violation-revenge relationship). This pattern of results suggests that perceived aggressive culture (and social learning) could potentially affect how employees behave, but perhaps not necessarily how they feel and think, following psychological contract breach. While this is consistent with the arguments we advanced for the effects of social learning in highly aggressive cultures, it is inconsistent with the argument that social information processing would influence how employees construe situations.

Finally, a major aspect of our theory-building efforts pertains to the integration of social learning and social information processing theories with the general theory of crime in response to the calls to consider the interplay between individual and situational predictors in explaining workplace deviance (Aquino et al., 2004). Although progress has been made in understanding how one's personality (e.g., Douglas \& Martinko, 2001) and perceptions of the work situation (e.g., Aquino et al., 2004) relate to workplace deviance, research has rarely empirically assessed the joint effects of these two classes of moderating variables. In their recent study, Bordia and colleagues (2008) developed and found support for a process model linking cognitions of breach, violation, revenge cognitions, and workplace deviance. They also found initial evidence that self-control moderated the relationship between revenge cognitions and workplace deviance. However, they did not test the role of selfcontrol within each stage of their proposed model. In addition, while Bordia and colleagues examined a dispositional variable (i.e., self-control) in their model, they did not consider the role of contextual factors such as perceived aggressive work culture that could potentially influence the resulting responses to breach. We believe that our article extends their work not only by developing predictions about self-control but also by integrating the role of perceived aggressive work culture within each stage of their model. Results across the two samples in our study demonstrate that the combined effects of self-control and perceived aggressive work culture provide a more comprehensive explanation for why deviance does or does not occur. In particular, we found a significant conditional indirect effect (second-stage moderation only) for low self-control and high aggressive culture within the psychological contract violation-revenge-workplace deviance relationship.

To this end, what theoretical insights can be derived from these results? After the individual realizes that she or he feels violated and contemplates seeking revenge, this individual engages in thought processes in which information regarding the transgressor's intent and the feasibility of engaging in the act is evaluated (Anderson \& Bushman, 2002). Depending on perceived environmental factors (e.g., perceived aggressive culture) and the individual's disposition (e.g., self-control), the individual may further engage in a secondary sense-making process in which informational cues are more consciously evaluated. For example, employees with high self-control who perceive a highly aggressive culture may engage in more thoughtful processes, as self-regulation affords them more time to think about the situation. This could also be a function of the ability to detach themselves from the current situation and reflect about the long-term ramifications of their 
subsequent actions (Muraven \& Baumeister, 2000). In contrast, employees with low self-control who perceive a highly aggressive culture may fail to override their sense of anger and initial revenge motivations that drive them to enact aggressive behaviors. Indeed, Dodge and Newman (1981) noted that careful and prolonged processing of information is needed to mitigate the effects of initial hostile interpretations. Overall, our results are novel in that they offer insights on just when workplace deviance is likely to take place.

We also believe that the absence of empirical support for the other three-way interactions makes an important contribution to the literature, as it demonstrates that the effects of perceived aggressive work culture and self-control do not influence emotional and cognitive reactions to breach. The fine-grained analyses we have undertaken to understand the unfolding process of psychological contract breach suggests that the interactive forces between self-control and perceived aggressive work culture are not particularly salient in predicting employees' negative affective and revenge reactions. This is perhaps due to the fact that the resulting emotions and cognitions may have occurred rapidly upon exposure to a psychological contract breach event. It could also be that engaging in these negative emotive and cognitive responses does not have a direct consequence for the individual employee and therefore are less likely to be regulated.

\section{Strengths, Limitations, and Future Directions}

The current research has several methodological strengths. First, we have taken steps to minimize same-source variance and to strengthen internal validity. For instance, self-reports of breach and revenge cognitions may be contaminated by social desirability motives. To test for these effects, we measured social desirability and incorporated it in our statistical analysis. In addition, we incorporated a temporal element in assessing the variables (e.g., the use of a one month lag in Sample 2). Second, we obtained peer reports of workplace deviance in order to minimize same-source bias. The fact that we found consistent results when peer reports (Sample 1) and self-reports (Sample 2) of workplace deviance were utilized strengthens the validity of our results. A third methodological strength involves a constructive replication of the predicted relationships. Replication of results across samples is critical to generalization, as findings that are not replicated are "virtually meaningless and useless" (Lindsay \& Ehrenberg, 1993: 219). Indeed, recent research by Schmidt (2009) stresses the important - and largely neglected - role of replication in the behavioral sciences. Finally, the diversity of our participants, drawn from two countries (e.g., Australia and the Philippines), provides evidence that the interplay of revenge, self-control, and perceived aggressive work culture in predicting deviance may be consistent across cultural contexts within the hospitality industry.

This study has several limitations as well. A major limitation of our work concerns the cross-sectional design. The nature of the research designs employed in both Samples 1 and 2 preclude us from inferring cause-and-effect associations in the process model we have outlined. Second, our operationalization of psychological contract breach is based on the assumption that this phenomenon takes place only when individuals perceive that they have received less than what was promised. ${ }^{1}$ Indeed, Lambert, Edwards, and Cable (2003) noted 
that this represents a restricted view of psychological contract breach because receiving too much may also result in negative outcomes (e.g., overfulfillment — too many developmental experiences may result in reduced job satisfaction). Third, perceived aggressive work culture was based on self-report data. Thus, we were unable to validate the authenticity of employees' perceptions of aggressive culture using a peer-rated measure. Fourth, alternative moderators were not included in the model. For example, procedural justice climate refers to how individuals perceive the fairness of rules or procedures that regulate decision processes (Liao \& Rupp, 2005). Theoretically, a strong procedural justice climate could minimize workplace deviance. Furthermore, anger rumination - an unintentional recurring cognitive process related to anger experience and expression (Denson, 2009) - could amplify the violation-revenge cognition-deviance relationships. Finally, although we have attempted to minimize common method variance by collecting peer ratings of workplace deviance in Sample 1, we acknowledge that even with the observable behaviors, individuals often enact deviant behaviors away from watchful eyes. ${ }^{2}$

\section{Practical Implications}

An important practical implication that can be drawn from this article is the need to take into account the self-control and perceived aggressive work culture interaction as a joint predictor of workplace deviance for purposes of recruitment. The current research explicitly demonstrated the delicate interplay between self-control and perceived aggressive work culture in influencing whether revenge (as a by-product of violation) will actually lead to aggressive behaviors. For example, aggressive employees would be most volatile in an organization perceived to have a highly aggressive culture, but employees would be more likely to be tolerant and understanding of others' shortcomings if the organization promoted such behavior. Notably, recruiters should not only hire individuals based on their dispositions (i.e., high levels of self-control) but also carefully consider the environments in which the individuals will be working. Similarly, it is not recommended that organizations prioritize resources around developing ideal organizational environments if employees' personalities do not fit this work culture (Snyder, Berscheid, \& Matwychuk, 1988). Instead, recruiters should carefully consider the interaction between dispositional and environmental factors when determining whether a potential employee will engage in problematic behaviors in the workplace.

\section{Notes}

1. We thank an anonymous reviewer for making this important point about an expanded view of psychological contract breach.

2. We thank an anonymous reviewer for helpful suggestions related to the general discussion.

\section{References}

Anderson, C. A., \& Bushman, B. J. 2002. Human aggression. Annual Review of Psychology, 53: 27-51.

Aquino, K., Douglas, S., \& Martinko, M. J. 2004. Overt expressions of anger in response to perceived victimization: The moderating effects of attributional style and organizational norms. Journal of Occupational Health Psychology, 9: 152-164. 
Aquino, K., Tripp, T., \& Bies, R. 2006. Getting even or moving on? Power, procedural justice, and types of offense as predictors of revenge, forgiveness, reconciliation, and avoidance in organizations. Journal of Applied Psychology, 91: 653-658.

Bandura, A. 1986. Social foundations of thought and action. Englewood Cliffs, NJ: Prentice Hall.

Baumeister, R. F., \& Heatherton, T. F. 1996. Self-regulation failure: An overview. Psychological Inquiry, 7: 1-15.

Baumeister, R. F., Heatherton, T. F., \& Tice, D. M. 1994. Losing control: How and why people fail at selfregulation. San Diego, CA: Academic Press.

Berkowitz, L. 1993. Aggression: Its causes, consequences, and control. Philadelphia: Temple University Press.

Bernardo, A. B. I. 2004. McKinley's questionable bequest: Over 100 years of English in Philippine education. World Englishes, 23: 17-31.

Bies, R. J., Tripp, T. M., \& Kramer, R. M. 1997. At the breaking point: Cognitive and social dynamics of revenge in organizations. In R. Giacalone \& J. Greenberg (Eds.), Anti-social behavior in organizations: 18-36: Thousand Oaks, CA: Sage.

Bordia, P., Restubog, S. L. D., Bordia, S., \& Tang, R. L. 2010. Breach begets breach: Trickle-down effects of psychological contract breach on customer service. Journal of Management, 36: 1578-1607.

Bordia, P., Restubog, S. L. D., \& Tang, R. L. 2008. When employees strike back: Investigating the mediating mechanisms between psychological contract breach and workplace deviance. Journal of Applied Psychology, 93: 1104-1117.

Bradfield, M., \& Aquino, K. 1999. The effects of blame attributions and offender likeableness on revenge and forgiveness in the workplace. Journal of Management, 25: 607-631.

Brown, S. P., Westbrook, R. A., \& Challagalla, G. 2005. Good cope, bad cope: Adaptive and maladaptive coping strategies following a critical negative work event. Journal of Applied Psychology, 10: 147-165.

Campbell, A., \& Muncer, S. 1990. Causes of crime. Criminal Justice and Behavior, 17: 410-419.

Cooke, R. A., \& Szumal, J. L. 1987. Interpreting the cultural styles measured by the OCI. In R. A. Cooke (Ed.), Organizational culture inventory: Level V, leaders manual: 27-56: Plymouth, MI: Human Synergistics.

Denson, T. F. 2009. Angry rumination and the self-regulation of aggression. In J. P. Forgas, R. F. Baumeister, \& D. M. Tice (Eds.), The psychology of self-regulation: 233-248: New York: Psychology Press.

Denson, T. F., DeWall, C. N., \& Finkel, E. J. in press. Self-control and aggression. Current Directions in Psychological Science.

Dodge, K. A., \& Newman, J. P. 1981. Biased decision making processes in aggressive boys. Journal of Abnormal Psychology, 90: 375-379.

Douglas, S. C., \& Martinko, M. J. 2001. Exploring the role of individual differences in the prediction of workplace aggression. Journal of Applied Psychology, 86: 547-559.

Emerson, R. 1976. Social exchange theory. Annual Review of Sociology, 2: 335-362.

Flanagan, J. C. 1954. The critical incident technique. Psychological Bulletin, 51: 327-358.

Folger, R., \& Skarlicki, D. P. 1998. A popcorn metaphor for workplace violence. In R. W. Griffin, A. O’Leary-Kelly, \& J. Collins (Eds.), Dysfunctional behavior in organizations: Violent and deviant behavior (Vol. 23): 43-81: Greenwich: JAI Press.

Gakovic, A., \& Tetrick, L. E. 2003. Perceived organizational support and work status: A comparison of the employment relationships of part-time and full-time employees attending university classes. Journal of Organizational Behavior, 24: 649-666.

Geen, R. G. 1990. Human aggression. Pacific Grove, CA: Brooks/Cole.

Gottfredson, M. R., \& Hirschi, T. 1990. A general theory of crime. Stanford, CA: Stanford University Press.

Grasmick, H. G., Tittle, C. R., Bursik, R. J., \& Arneklev, B. J. 1993. Testing the core empirical implications of Gottfredson and Hirschi's general theory of crime. Journal of Research in Crime and Delinquency, 30: 5-29.

Kiewitz, C., Restubog, S. L. D., Zagenczyk, T. J., \& Hochwarter, W. 2009. The interactive effects of psychological contract breach and organizational politics on perceived organizational support: Evidence from two longitudinal studies. Journal of Management Studies, 46: 806-834.

Lambert, L. S., Edwards, J. R., \& Cable, D. M. 2003. Breach and fulfillment of the psychological contract: A comparison of traditional and expanded views. Personnel Psychology, 56: 895-934.

Liao, H., \& Rupp, D. E. 2005. The impact of justice climate and justice orientation on work outcomes: A cross-level multifoci framework. Journal of Applied Psychology, 90: 242-256. 
Lindsay, R., \& Ehrenberg, A. 1993. The design of replicated studies. American Statistician, 47: 217-228.

Low, C. H., \& Bordia, P. 2011. A career stage perspective on employees' preferred psychological contract contributions and inducements. Journal of Management and Organization, 17: 729-746.

Morrison, E. W., \& Robinson, S. L. 1997. When employees feel betrayed: A model of how psychological contract develops. Academy of Management Review, 22: 226-256.

Muraven, M., \& Baumeister, R. F. 2000. Self-regulation and depletion of limited resources: Does self-control resemble a muscle? Psychological Bulletin, 126: 247-259.

Podsakoff, P. M., \& Organ, D. W. 1986. Self-reports in organizational research: Problems and prospects. Journal of Management, 12: 531-544.

Preacher, K. J., Rucker, D. D., \& Hayes, A. F. 2007. Assessing moderated mediation hypotheses: Theory, methods, and prescriptions. Multivariate Behavioral Research, 42: 185-227.

Restubog, S. L. D., Bordia, P., \& Bordia, S. 2011. Investigating the role of psychological contract breach on career success: Convergent evidence from two longitudinal studies. Journal of Vocational Behavior, 7: 428-437.

Restubog, S. L. D., Hornsey, M., Bordia, P., \& Esposo, S. 2008. Effects of psychological contract breach on organizational citizenship behaviors: Insights from the group value model. Journal of Management Studies, 45: 1377-1400.

Robinson, S. L., \& Bennett, R. J. 1995. A typology of deviant workplace behaviors: A multidimensional scaling study. Academy of Management Journal, 38: 555-572.

Robinson, S. L., \& Morrison, E. W. 2000. The development of psychological contract breach and violation: A longitudinal study. Journal of Organizational Behavior, 21: 525-546.

Robinson. S. L., \& O’Leary-Kelly, A. M. 1998. Monkey see, monkey do: The influence of work groups on the antisocial behavior of employees. Academy of Management Journal, 41: 658-672.

Robinson, S. L., \& Rousseau, D. M. 1994. Violating the psychological contract: Not the exception but the norm. Journal of Organizational Behavior, 15: 245-259.

Rousseau, D. M. 1989. Psychological and implied contracts in organizations. Employee Rights and Responsibilities Journal, 2: 121-139.

Rousseau, D. M. 1995. Psychological contracts in organizations: Understanding written and unwritten agreements. Thousand Oaks, CA: Sage.

Salancik, G. R., \& Pfeffer, J. 1978. A social information processing approach to job attitudes and task design. Administrative Science Quarterly, 23: 224-253.

Sarchione, C. D., Cuttler, M. J., Muchinsky, P. M., \& Nelson-Gray, R. O. 1998. Prediction of dysfunctional job behaviors among law enforcement officers. Journal of Applied Psychology, 83: 904-912.

Schmidt, S. 2009. Shall we really do it again? The powerful concept of replication is neglected in the social sciences. Review of General Psychology, 13: 90-100.

Scott, W. A. 1965. Values and organizations: A study of fraternities and sororities. Chicago: Rand-McNally.

Snyder, M., Berscheid, E., \& Matwychuk, A. 1988. Orientations toward personnel selection: Differential reliance on appearance and personality. Journal of Personality and Social Psychology, 54: 972-979.

Strahan, R., \& Gerbasi, K. C. 1972. Short, homogeneous versions of the Marlowe-Crowne Social Desirability Scale. Journal of Clinical Psychology, 28: 191-193.

Tangney, J. P., Baumeister, R. F., \& Boone, A. L. 2004. High self-control predicts good adjustment, less pathology, better grades, and interpersonal success. Journal of Personality, 72: 271-322.

Turnley, W. H., Bolino, M. C., Lester, S. W., \& Bloodgood, J. M. 2003. The impact of psychological contract fulfillment on the performance of in-role and organizational citizenship behaviors. Journal of Management, 29: 187-206.

Weiss, H. M., \& Cropanzano, R. 1996. Affective events theory: A theoretical discussion of the structure, causes, and consequences of affective experiences at work. Research in Organizational Behavior, 18: 1-74.

Zagenczyk, T. J., Restubog, S. L. D., Kiewitz, C., Kiazad, K., \& Tang, R. in press. Psychological contracts as a mediator between Machiavellianism and employee citizenship and deviant behaviors. Journal of Management.

Zagenczyk, T. J., Scott, K. D., Gibney, R., Murrell, A. J., \& Thatcher, J. B. 2010. Social influence and perceived organizational support: A social network analysis. Organizational Behavior and Human Decision Processes, 111: $127-138$.

Zhao, H., Wayne, S. J., Glibkowski, B. C., \& Bravo, J. 2007. The impact of psychological contract breach on workrelated outcomes: A meta-analysis. Personnel Psychology, 60: 647-680. 